\title{
Large capacity magazines and homicide
}

\author{
Carlisle E. Moody \\ College of William and Mary
}

College of William and Mary

Department of Economics

Working Paper Number 160

February, 2015 
COLLEGE OF WILLIAM AND MARY

DEPARTMENT OF ECONOMICS

WORKING PAPER \# 160

February, 2015

\title{
Large capacity magazines and homicide
}

\begin{abstract}
Recent events have resulted in calls to ban large capacity magazines (LCMs) holding more than 10 rounds of ammunition. Using data from a Virginia data base of crime guns seized by police between 1993 and 2013, we find that the proportion of crime guns with LCMs declined after the 1994 Federal assault weapons ban and increased after the ban was lifted in 2004. However, we can find no evidence that LCMs increased either murder or gun murder, implying that the Federal LCM ban did not have the intended effect and that LCM bans are likely to be ineffective.
\end{abstract}

Key words: large capacity magazines, homicide, gun homicide JEL code: K42

Carlisle E. Moody

Economics Department

College of William and Mary

Williamsburg, VA 23187-8795

cemood@wm.edu 


\section{Introduction.}

Public shootings in Arizona, Colorado, Connecticut, and elsewhere have resulted in calls for the banning of firearm magazines with capacity of more than 10 rounds of ammunition. The primary argument for banning large capacity magazines (LCMs) is that a shooter is able to fire a large number of bullets before having to stop and reload. With smaller magazines, the number of shots fired would presumably be reduced and the number of victims, both killed and wounded, would be smaller. According to Senator Christopher Murphy, 'I believe, and many of the parents there believe, that if Lanza had to switch cartridges nine times versus two times there would likely still be little boys and girls alive in Newtown today.'1 According to a study published in Mother J ones, of the 143 weapons used in multiple victim public shootings from 1982-2012, 42 had magazines which held more than ten rounds and more than half the shooters possessed firearms with large capacity magazines. Also, as the following quote from the same article notes, the overall murder rate might also be affected by large capacity magazines.

By far the most common weapons used in these cases are semi-automatic handguns-the type of weapon also at the heart of the daily gun violence plaguing American communities. Banning high-capacity magazines may be especially key with regard to these guns, not only because they're popular among mass shooters, but also because they tend to increase casualties in street violence, ....2

\footnotetext{
${ }^{1}$ http:/ / www.nytimes.com/ 2013/ 02/ 19/ us/politics/lawmakers-look-at-ban-on-highcapacity-gun-magazines.html? $\mathrm{r}=0$ ${ }^{2}$ http:// www.motherjones.com/ politics/2013/02/ assault-weapons-high-capacitymagazines-mass-shootings-feinstein
} 
Opponents argue that it only takes a few seconds to eject a spent magazine and insert a full one and shooters frequently carry more than one firearm, which makes reloading unnecessary. They also argue that individuals might need LCMs in self-defense, especially when outnumbered, and that even experienced users miss their targets when under stress, perhaps necessitating more than a few shots before their assailants might be discouraged.

The most prominent academic study on the effect of LCMs is Koper and Roth (2001), based on an earlier study (Roth and Koper 1997) of the 1994 Federal ban of assault weapons, which included a ban of magazines with capacity greater than 10 . The study, using data from the first two years of the ban, found a statistically insignificant 6.7 percent decline in gun homicides. They conclude (p.69)

The law has not produced a clear impact on gun violence, based on data available less than 2 years following implementation of the law.... In time, the ban may be seen as an effective prevention measure which prevented further spread of this group of weapons. Even this conclusion will be contingent, however, on research which more clearly demonstrates that criminal attacks with these weapons are more lethal than attacks with other guns and magazines.

Kleck (2001) argues that a 6.7 percent reduction in gun homicide is clearly an overestimate and that the ban on LCMs could not be expected to have any measurable effect. According to Kleck,

In the decade before the AW ban, in the entire nation there were 15 mass shooting incidents in which more than 6 victims were killed or more than 12 were killed or 
wounded. Even in these few extreme cases, LCMs had no discernible effect on the number of victims because, in 14 of the 15 cases, either the shooter possessed multiple guns, which made it unnecessary for him to reload once one gun was empty, or the shooter in fact reloaded...And in more ordinary shootings, far fewer rounds are fired, as the authors concede (p. 41): 2.7 shots per semiauto gun homicide. In sum, neither LCMs nor the slightly higher rates of fire of semiauto guns affected the outcomes of any known incidents of gun violence, regardless of their hypothetical potential to increase the number of victims. (Kleck 2001, p. 79)

A more recent study by Koper et al (2004) updated the earlier study. It concluded that, ' ... it is conceivable that the ban slowed the rate of growth in LCM use, accelerated it temporarily (due to a pre-ban production boom), or had no effect. We do not have the data necessary to examine this issue rigorously. Moreover, the issue might be regarded as somewhat superfluous; the more critical point would seem to be that nearly a decade after the ban, LCM use has still not declined demonstrably below pre-ban levels.' (p.79)

However, the authors remain optimistic, 'Nonetheless, reducing crimes with AWs [assault weapons] and especially LCMs could have nontrivial effects on gunshot victimizations. As a general matter, hit rates tend to be low in gunfire incidents, so having more shots to fire rapidly can increase the likelihood that offenders hit their targets, and perhaps bystanders as well.' (Koper et al 2004, p.97) 
In 2011 the Washington Post published the results of its study of a little-known database on weapons recovered by local law enforcement officers in Virginia. The Criminal Firearms Clearinghouse, maintained by the Virginia State Police, contains detailed information on each firearm’s physical characteristics, including magazine capacity. The story noted that, 'The number of guns with high-capacity magazines seized by Virginia police dropped during a decade-long federal prohibition on assault weapons, but the rate has rebounded sharply since the ban was lifted in late 2004....' Two researchers were quoted in the story: 'Maybe the federal ban was finally starting to make a dent in the market by the time it ended,' said Christopher Koper, head of research at the Police Executive Research Forum, who studied the assault weapons ban for the National Institute of Justice, the research arm of the Justice Department. 'The pattern in Virginia 'may be a pivotal piece of evidence' that the assault weapons ban eventually had an impact on the proliferation of high-capacity magazines on the streets,' said Garen Wintemute, head of the Violence Prevention Research Program at the University of California at Davis. 'Many people, me included, were skeptical about the chances that the magazine ban would make a difference back in 1994,' Wintemute said. 'But what I am seeing here is that after a few years' lag time the prevalence of high-capacity magazines was declining. The increase since the ban's repeal is quite striking.' 3

\footnotetext{
${ }^{3}$ http://www.washingtonpost.com/wp-dyn/content/story/2010/12/14/ST2010121406431.html?sid=ST2010121406431
} 
II. A Test of the LCM Lethality Hypothesis.

The proportion of recovered firearms in the Virginia Criminal Firearms Clearinghouse with magazine capacity greater than 10 is shown in Figure 1 along with the corresponding murder and gun murder rate for Virginia from 1993 to $2013 .{ }^{4}$ The proportion of crime guns with LCMs initially rose from 1994-97 then declined steadily to 2004, only to rise again after the ban was lifted. On the other hand the murder rate and the gun homicide rate in Virginia have both declined steadily since 1990, revealing no apparent connection between homicide and the prevalence of LCMs.

This observation can be tested with the following simple model. We regressed the Virginia gun homicide rate and overall murder rate, in natural units and logs, in levels and in differences, on the proportion of crime guns with LCMs and a trend term for 1993-2013. The results are reported in Table 1. If we omit the trend, the estimated coefficient on the proportion of LCMs is negative and highly significant, reflecting the fact that crime in Virginia continued its decline while the proportion of crime guns with large capacity magazines increased substantially after 2004. However, when we include the trend, which is negative and highly significant, the proportion of LCMs is never significant. ${ }^{5}$

\footnotetext{
${ }^{4}$ Murder data is taken from the Uniform Crime Reports. Gun homicide is taken from the CDC Wonder data base. All data, programs and results can be downloaded from the author's web site.

${ }^{5}$ Table 1 reports the Breusch-Godfrey test for autocorrelation. The regressions in levels show significant positive serial correlation, except for the log of the gun homicide rate, indicating that the t-ratios are likely to be overstated in those cases. In first differences the serial correlation is negative, indicating that the t-ratios are underestimated. We estimated the regression in both levels and first differences because, although unit root tests indicated nonstationarity in most cases, such tests have low power with small sample size. All of the regressions have residuals that appear to be stationary.
} 
The results are the same for gun homicides and murders using a negative binomial model. There is also no relationship between the number of public shooting victims and the proportion of LCMs because Virginia had only one such event, the Virginia Tech shooting in 2007 in which the shooter used both standard and large capacity magazines.

\section{Summary and Conclusion.}

Firearms fitted with large capacity magazines can be used to cause death and injury in public shooting incidents and can also result in more rounds fired and more homicides in general than similar firearms with smaller magazines. However, it is also possible for shooters to avoid the necessity of reloading by carrying several firearms, carry several magazines which can be exchanged quickly, or simply take the time to reload. Finally, police officers, security professionals, and private citizens can use firearms with large capacity magazines to protect themselves and others.

Gun control advocates frequently suggest that bans on LCMs are examples of common-sense gun control measures. For example, according to the Citizen's Crime Commission of New York City, 'Large capacity ammunition magazines carry far more bullets than any civilian could possibly ever use. Restricting the size of ammunition magazines to no more than 10 bullets is common sense. A ban on large capacity ammunition magazines would not only reduce the number of rounds in the gun, but more importantly reduce the lethality of these dangerous weapons. $^{, 6}$

\footnotetext{
${ }^{6}$ http://www.nycrimecommission.org/pdfs/LCMagsFACTSHEET.pdf
} 
Using the only data available with which to make a direct test of the LCM lethality hypothesis, we are unable to find any effect of LCMs or the Federal LCM ban on lethality measured as the number of murders, the murder rate, the number of gun homicides, the gun homicide rate, or deaths and injury caused by public shootings. Large capacity magazines appear to have little to do with homicide, public or private, and laws banning these products apparently have no effect. 


\section{References}

Kleck, G. (2001) Impossible policy evaluations and impossible conclusions: a comment on Koper and Roth, Journal of Quantitative Criminology 17, 75-80.

Koper, C. S. and Roth, J. A. (2001) The impact of the 1994 federal assault weapon ban on gun violence outcomes: an assessment of multiple outcome measures and some lessons for policy evaluation, Journal of Quantitative Criminology 17, 33-74.

, Woods, D. J. and Roth, J. A. (2004) An updated assessment of the federal assault weapons ban: impacts on gun markets and gun violence, 1994-2003: report to the National Institute of Justice, United States Department of Justice. Available at http://www.feinstein.senate.gov/public/index.cfm/files/serve/?File_id=b531daeb-a954-41f8a21c-268cceccb4c4 (accessed 10 February 2015).

Roth, J.A. and Koper, C.S. (1997) Impact evaluation of the Public Safety and Recreational Firearms Use Protection Act of 1994: final report. Available at http://www.urban.org/UploadedPDF/406797_aw_final.pdf (accessed 10 February 2015). 
Table 1

\begin{tabular}{|c|c|c|c|c|c|c|}
\hline \multirow[t]{2}{*}{ Variable } & \multicolumn{2}{|l|}{ Pctlcm } & \multicolumn{2}{|l|}{ Trend } & \multicolumn{2}{|c|}{ Autocorrelation } \\
\hline & Coeff & T-ratio & Coeff & T-ratio & Rho & T-ratio \\
\hline Gun homicide rate & -0.109 & $-2.54 * *$ & & & 0.713 & $5.15^{* * *}$ \\
\hline with trend & -0.008 & -0.03 & -0.151 & $-6.53 * * *$ & 0.417 & $1.78^{*}$ \\
\hline First differences & -0.027 & -0.07 & -0.158 & -1.23 & -0.552 & $-2.56 * *$ \\
\hline Log gun homicide rate & -0.028 & $-3.03 * * *$ & & & 0.694 & $4.52 * * *$ \\
\hline with trend & -0.006 & -1.03 & -0.033 & $-6.86 * * *$ & 0.299 & 1.21 \\
\hline First differences & -0.006 & -0.67 & -0.037 & -1.26 & -0.593 & $-2.58 * *$ \\
\hline Murder rate & -0.140 & $-2.48 * *$ & & & 0.774 & $6.03 * * *$ \\
\hline with trend & -0.021 & -0.67 & -0.217 & $-8.49 * * *$ & 0.583 & $2.79 * *$ \\
\hline First differences & -0.004 & -0.12 & -0.221 & $-1.83^{*}$ & -0.411 & $-1.87^{*}$ \\
\hline Log murder rate & -0.027 & $-2.91 * * *$ & & & 0.744 & $4.96 * * *$ \\
\hline with trend & 0.000 & -0.06 & -0.036 & $-8.86 * * *$ & 0.480 & $2.16^{* *}$ \\
\hline First differences & 0.006 & 0.10 & -0.039 & $-1.84^{*}$ & -0.459 & $-2.03^{*}$ \\
\hline Gun murders & -0.021 & $-3.03 * * *$ & & & & \\
\hline with trend & -0.007 & -1.20 & -0.021 & $-4.73 * * *$ & & \\
\hline Murders & -0.019 & $-2.78 * * *$ & & & & \\
\hline with trend & -0.001 & -0.16 & -0.024 & $-6.33 * * *$ & & \\
\hline
\end{tabular}

Notes: ${ }^{* * *}$ significant at .01, ** significant at $.05,{ }^{*}$ significant at .10, two-tailed. Pctlcm is the proportion of Virginia crime guns with large capacity magazines. In the first difference model the trend is estimated by the intercept. Gun murders and murders are estimated using a negative binomial model. All programs, data, and output can be downloaded from the author's web site. 
Figure 1

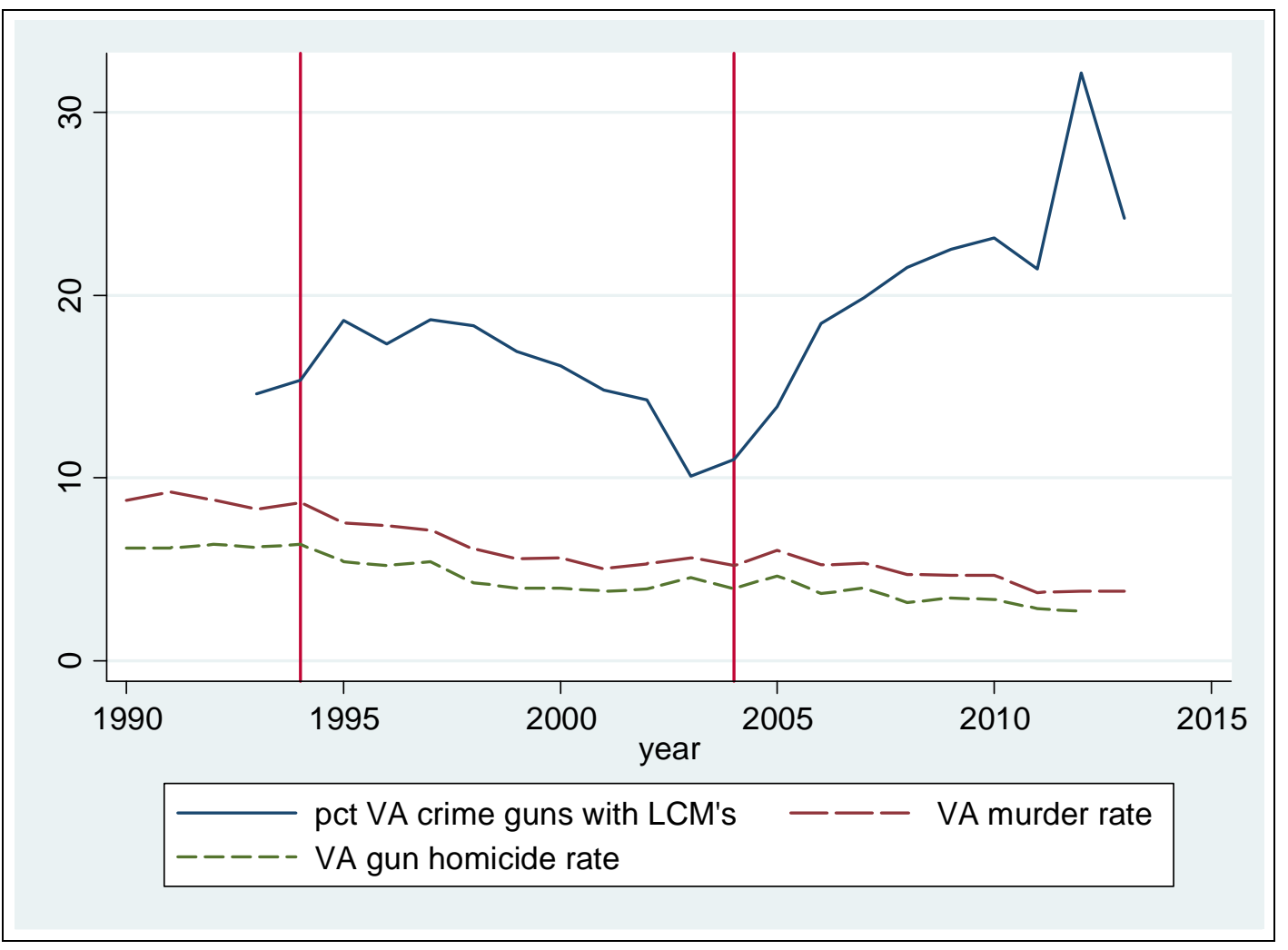

